\title{
Wheel-running activity during ad lib and food-deprivation conditions in four inbred mouse strains
}

\author{
JAMES P. SYMONS* \\ Syracuse University, Syracuse, N.Y. 10310
}

The wheel-running hierarchy of four inbred mouse strains (C57BL/6J, C3H/HeJ, BALB/cJ, and CBA/J) under ad lib food condition was compared to the exploratory activity hierarchy of the same strains. Although there was a difference in the hierarchies, this difference could be accounted for by the shift in position of the C57BL/6J strain from most active in the exploratory situation to third most active in the wheel-running situation. Under a 50\% ad lib food-deprivation regimen, two effects were found. First, CBA/J mice differed from the other strains by decreasing wheel-running rate during the deprivation period, whereas the other strains showed an increase; and second, BALB/cJ and $\mathrm{C} 3 \mathrm{H} / \mathrm{HeJ}$ mice died early in the deprivation period. This early death rate may be the result of a more rapid weight loss when compared to C57BL/6J and CBA/J mice.

Most behavioral tasks used to assess the performance of experimental animals contain an obvious activity component. However, the relationships among the various types of activity which contribute to performance in these tasks (e.g., running, jumping, barpressing, and exploration) have not yet been subjected to systematic study. Such relationships may be an important source of information in attempts to relate the performance of Ss in several behavioral situations. Two commonly used indices of activity are performance in a wheel-turning situation and exploratory behavior in an open-field test (Campbell \& Lynch, 1967, 1968; McClearn, 1960, 1961).

The performance of inbred mouse strains may be used to detect genetic influence upon behavioral measures. Where strain differences in behavior occur, it is likely that differences in underlying mechanisms are also present.

Bruell (1964) has noted strain differences in wheel-running activity when animals were tested for limited periods of time, i.e., $6 \mathrm{~h}$ per strain. Differences in exploratory activity have also been found in a number of inbred mouse strains (Thompson, 1953, 1956; McClearn, 1960, 1961; Southwick \& Clark, 1966). However, the relationship between the strain hierarchy in exploratory

*Present address: The Jackson Laboratory, Bar Harbor, Maine 04609. Research was conducted as partial fulfillment of the requirement for the Master of Science Degree. I am grateful for the assistance of Dr. Richard L. Sprott, The Jackson Laboratory, in preparation of the manuscript. Preparation of the manuscript was supported in part by NIH Grant HD 05523 from the National Institute of Child Health and Human Development. The Jackson Laboratory is fully accredited by the American Association for Accreditation of Laboratory Animal Care. Richard L. Sprott sponsored this manuscript and takes full editorial responsibility. activity and hierarchy on wheel running has not been determined.

The relationship between the two activity measures could take at least two forms. First, if strains differ on a generalized activity level (McClearn \& Meredith, 1964), then mice of strains that were active in the exploratory field might be expected to be active in running wheels. On the other hand, if strains differ on different tasks and reflect different underlying mechanism, then running wheel activity could differ from exploratory activity (Treichler \& Hall, 1962).

In order to explore the relationship, four strains which were known to differ on exploratory activity were tested to determine the activity hierarchy in running wheels. This strain ordering was then compared to the hierarchy of exploratory activity as determined by Thompson $(1953,1956)$, McClearn $(1960,1961)$, and Southwick \& Clark (1966). In addition, since food deprivation often increases running activity (Campbell et al, 1966; Campbell \& Lynch, 1967, 1968), the effect of food deprivation on wheel running was investigated to discern whether it alters the wheel-running hierarchy of the four strains.

\section{PROCEDURE}

Four strains of mice, $\mathrm{C} 3 \mathrm{H} / \mathrm{HeJ}, \mathrm{C} 57 \mathrm{BL} / 6 \mathrm{~J}, \mathrm{BALB} / \mathrm{cJ}$, and CBA/J (hereafter referred to as $\mathrm{C} 3 \mathrm{H}, \mathrm{C} 57, \mathrm{BALB}$, and CBA, respectively), were obtained from The Jackson Laboratory, Bar Harbor, Maine, at 60 days of age. Thirteen Ss were used from the $\mathrm{C} 3 \mathrm{H}, \mathrm{C} 57$, and $\mathrm{CBA}$ strains and 12 from the BALB strain. When the animals were 120 days old, they were placed individually in 14-in.diam Wahmann running wheels. After a 10-day adaptation period in which no measures were taken, a 10-day ad lib period followed when food and water were available continually. Measures were taken in this period of wheel running (revolutions/24 h), food and water intake, and body weight. Based on individual animal's daily food intake during the ad lib period, half of the Ss of each strain were placed on a food-deprivation schedule (50\% of ad lib intake). This schedule was used because pilot work with white Swiss mice indicated an ability to survive on $50 \%$ food for long deprivation periods. The Ss were matched for wheel running under ad lib conditions. Following the deprivation period, food was again made available ad lib, with measures of wheel running, food and water intake, and body weight taken daily until running returned to baseline.

\section{RESULTS AND DISCUSSION}

Under ad lib food conditions, the wheel-running hierarchy differed from the exploratory activity hierarchy. In the latter activity, the C57 strain is the most active, while the $\mathrm{C} 3 \mathrm{H}$ strain is most active in the running wheel. The hierarchies from most active to least active were $\mathrm{C} 3 \mathrm{H}, \mathrm{CBA}, \mathrm{C} 57$, and BALB for wheel running (ad lib) and $\mathrm{C} 57, \mathrm{C} 3 \mathrm{H}, \mathrm{CBA}$, and BALB for 


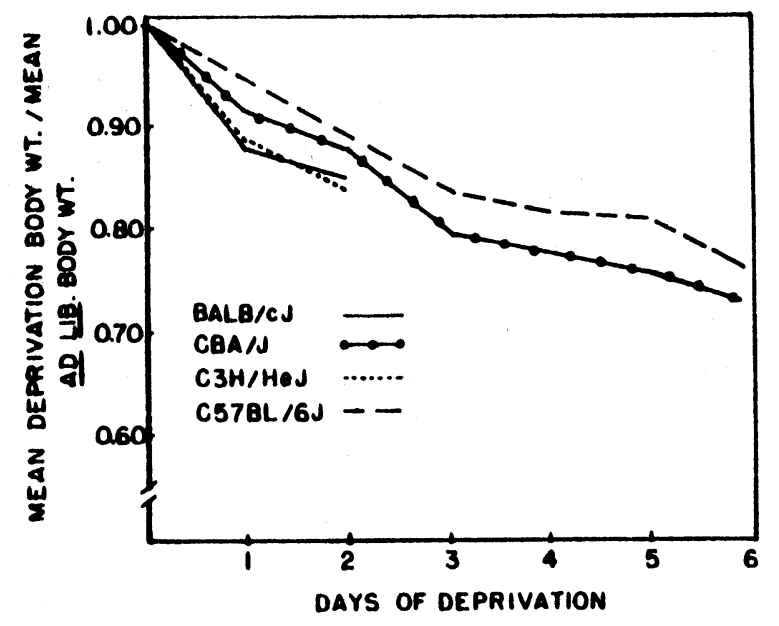

Fig. 1. The ratio of mean deprivation body weight to mean ad lib body weight over deprivation days for four strains of mice.

exploratory activity (Thompson, 1953, 1956; Southwick \& Clark, 1966). The hierarchy difference is a reflection of the relative decrease in the activity level of C57 mice in wheel running.

Significant strain differences were found on wheel running during ad lib food conditions. These differences are mainly due to the high running rate of the $\mathrm{C} 3 \mathrm{H}$ strain. Thus, when Tukey comparisons are made between the strains following a significant analysis of variance across the four strains $(F=32.50, d f=3,47$, $\mathrm{p}<.001$ ), a number of strain differences are apparent. The $\mathrm{C} 3 \mathrm{H}$ strain differed significantly from the other three strains. The BALB and CBA strains differed from each other significantly, whereas the $\mathrm{C} 57$ strain did not differ from the BALB or CBA strain.

It appears that the C57 mice react to the two activity situations differently. Exploratory activity and wheel-running activity yield different levels of activity. The other strains, however, maintained their relative positions in the activity hierarchy.

Having established a strain hierarchy of wheel running, we then investigated the effect of food deprivation on wheel running. Two results of deprivation were found. First, food deprivation results in different survival rates for the four strains. The BALB and C3H mice died early in the deprivation period, while CBA and C57 mice were able to endure the full deprivation period. The BALB and $\mathrm{C} 3 \mathrm{H}$ mice probably die earlier during food deprivation because of a rapid weight loss. This rapid weight loss is also reflected in the high running rates for these two strains on the first deprivation day. Figure 1 presents the ratio of mean daily deprivation weight to mean ad lib body weight and indicates that the BALB and $\mathrm{C} 3 \mathrm{H}$ strain lose weight at a greater rate than the $\mathrm{C} 57$ or CBA strains.

The second effect of food deprivation on wheel running was to produce running rates which differed from the ad lib rates in the four strains. It was found that the mean running rates of two of the strains, $\mathrm{C} 3 \mathrm{H}$ and C57, during food deprivation exceeded the mean running rates of the same mice during the ad lib food condition, as well as the mean rates of nondeprived control Ss. The mean running rates of BALB mice appear relatively unchanged, although there is an increase in running rate on the first deprivation day. The CBA strain was the most unusual and differed from the other strains in that a gradual, but steady, decrease in wheel running occurred during the entire food-deprivation period. Figure 2 shows the mean daily running rate during ad lib (top) and food-deprivation conditions for the control and experimental groups (bottom).

The strain differences that were found in both ad lib

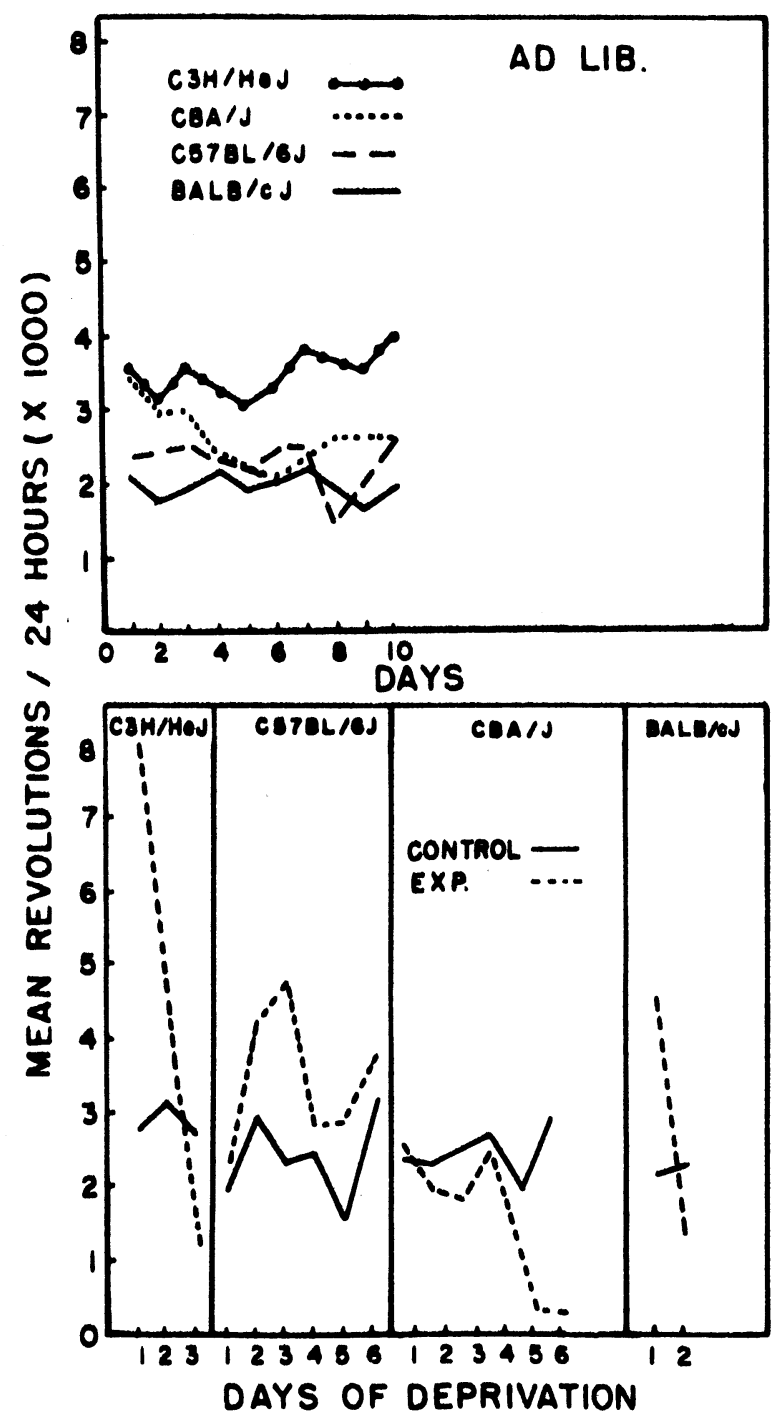

Fig. 2. Mean daily running rate for four strains of mice under ad lib conditions (top) and running rate during food deprivation for the same four strains of mice (bottom). 
and food-deprived conditions are important and should be noted whenever inbred mouse strains are used in behavioral research. The implication from the present research is that the genotypes of the various strains result in unique responses to behavioral situations, especially in the food-deprived state. This is clearly evident in the CBA strain, which responds to food deprivation by decreasing wheel running, whereas the remaining three strains increase. Further evidence of the genetic influence is also provided by the fact that two of the strains died early in the deprivation condition. Research in possible physiological mechanisms which accompany the various behavioral responses would be valuable in determining the genetic contribution to behavior.

\section{REFERENCES}

Bruell, J. H. Heterotic inheritance of wheel running in mice. Journal of Comparative \& Physiological Psychology, 1964, 58, 159-163.

Campbell, B. A., \& Lynch, G. S. Activity and thermoregulation during food deprivation in the rat. Physiology \& Behavior, 1967, 2, 311-313.
Campbell, B. A., \& Lynch, G. S. Influences of hunger and thirst on the relationship between spontaneous activity and body temperature. Journal of Comparative \& Physiological Psychology, 1968, 65, 492-498.

Campbell, B. A., Smith, N. F., Misanin, J. R., \& Jaynes, J. Species differences in activity during hunger and thirst. Journal of Comparative \& Physiological Psychology, 1966, 61, 123-127.

McClearn, G. E. Strain differences in activity of mice: Influence of illumination. Journal of Comparative \& Physiological Psychology, 1960, 53, 142-143.

McClearn, G. E. Genotvpe and mouse activity. Journal of Comparative \& Physiological Psychology, 1961, 54, 674-676.

McClearn, G. E., \& Meredith, W. Dimensional analysis of activity and elimination in a genetically heterogeneous group of mice (Mus musculus). Animal Behaviour, 1964, 12, 1-10.

Southwick, C. H. \& Clark, L. H. Aggressive behavior and exploratory activity in fourteen mouse strains. American Zoology, 1966, 6, 599 (abstract).

Thompson, W. R. The inheritance of behavior: Behavioral differences in fifteen mouse strains. Canadian Journal of Psychology, 1953, 7, 145-148.

Thompson, W. R. The inheritance of behavior: Activity differences in five inbred mouse strains. Journal of Heredity, $1956,47,147-148$

Treichler, F. R., \& Hall, J. F. The relationship between deprivation, weight loss, and several measures of activity. Journal of Comparative \& Physiological Psychology, 1962, 55, 346-349.

(Received for publication October 27, 1972.) 